\title{
Risk, business and
}

\section{e-commerce}

\author{
by Stephen Mason
}

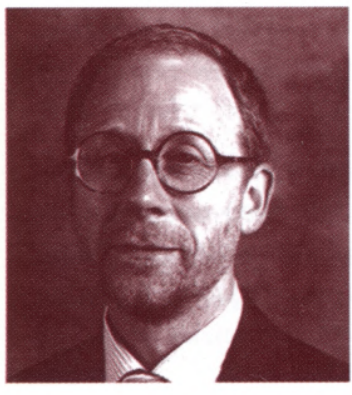

Stephen Maso
Common misperceptions about the benefits of Internet trading and investment have serious implications for businesses, individuals and governments, argues Stephen Mason, a barrister who specialises in e-commerce.
$\mathrm{I}$ magine this scenario if you will: seduced by the prospect of the anticipated level of profits, which in turn are based on the assumption that the new technology will radically alter the landscape, thousands of people invest their modest savings in the new companies formed almost overnight. Great strides are made, but companies fail for want of profit because the projections were incorrect. Many ordinary people lose precious savings as a result.

This does not describe the Internet at the turn of the second millennium, but the railway mania of the 19th century. The prediction that large quantities of goods would be transported by rail failed to live up to the promises, although passenger traffic was much higher than expected. Although many people lost money in the process of establishing a rail infrastructure, it is an asset that we continue to use today. It is probable that the same will occur with the commercial development of the Internet. Money will be lost by backing dot-com start-ups that never deserved to get beyond the imagination of the person that thought up the idea. However, the Internet will be used in the future for purposes that may be difficult to predict at present, just as the railways remain intrinsic to the transport structure of many countries world-wide today.

\section{THE INTERNET PHENOMENON}

The Internet has taken the European continent by storm in recent months. Immense wealth appears to have been created out of almost nothing. Companies that have been trading for anything between six months and two and a half years are floated on the stock exchange and are worth hundreds of millions overnight. Shares are oversubscribed many times as investors flock to buy a stake, knowing the company they are buying into will not make a profit for two, five or ten years, or even never make a profit in its trading history.

\section{THIS ARTICLE}

I am interested in the commercial development of the Internet because I seek to persuade people in business that their money is better spent in understanding the legal risks they face, rather than waiting for a mistake to occur that causes endless emotional turmoil, increased expenditure and a reduced focus on maintaining business continuity. In particular, my experience in e-commerce legal work has led me to identify, in broad terms, two types of person that take advantage of the opportunities offered by the Internet. In the first category are those who have carried on their terrestrial business for a number of years without consulting a lawyer. The people that fit into this category tend to establish a presence on the web without a thought to the legal issues they may face.

The people who fit into the second category differ markedly from those that have traded for a number of years. In the main, they have never been in business themselves. They usually have an idea that they wish to exploit on the Internet. People in this group tend to seek out legal advice before they take the idea any further. In general, they are cautious about protecting their idea, and recognise the potential dangers they face by trading on the Internet. They do not usually have any specific understanding of the issues they will be exposed to, but grasp the need to consider legal protection before doing anything else.

\section{IRRATIONAL BEHAVIOUR}

The emergence of companies that have been given substantial financial backing highlights an interesting aspect of human behaviour that is irrational. This is the provision of financial support for what is essentially an idea which, it is assumed, will (when implemented) make handsome profit, without any research to back up the assumptions.

However, it appears many people fail to undertake sufficient research to establish whether their business will succeed on the Internet. The aim of this article is to consider some of the assumptions made about the Internet by people in business, and how these assumptions do not accord with reality. In looking at the Internet from this perspective, the reader may gain an insight into the prevalent attitude to risk in the business world. 


\section{THE INTERNET FOR BUSINESS}

The Internet has many uses, in particular the provision of information. However, for the purposes of this article the focus will be on the Internet and its use by business. There are two markets: business to business trade and business to consumer trade. This article focuses on the business to consumer market.

Many people have made fantastic leaps of imagination when thinking about the potential offered by the Internet. It is assumed that a web site is available to everybody with access to the Internet, 24 hours a day, seven days a week. The current wisdom takes this one stage further with the proposition that this continuous availability gives unlimited opportunities to sell a vast array of goods and services world-wide. The market, so it is said, is so big than any business will succeed on the Internet. An antidote to this hyperbole is to recall the same vision articulated by western merchants when China was forced to open its market to trade after the opium wars. The anticipated volumes of unlimited trade never occurred.

That is not to say that all businesses trading on the Internet fail to achieve significant sales. Some businesses have done well. Pornography, entertainment, gambling and gaming sites have experienced considerable success, with 70 per cent of Internet pornography traffic occurring during the working day between $9 \mathrm{am}$ and $5 \mathrm{pm}$. Following well behind are businesses that sell goods and services. Some make excellent profits, and trading on the Internet has increased the size of their business beyond the corner shop. For instance, the daughters of Chris Battle, a butcher, encouraged him to spend $£ 1,000$ on a web site in 1997. His turnover increased from $£ 70,000$ in 1998 to $£ 750,000$ in 1999 . He closed the family shop that had been open for 103 years, and recruited a further 11 members of staff to complement the original two employees. This modest success story illustrates the value of trading on the Internet.

The emergence of companies that have been given substantial financial backing highlights an interesting aspect of human behaviour that is irrational. This is the provision of financial support for what is essentially an idea which, it is assumed, will (when implemented) make handsome profit, without any research to back up the assumptions.

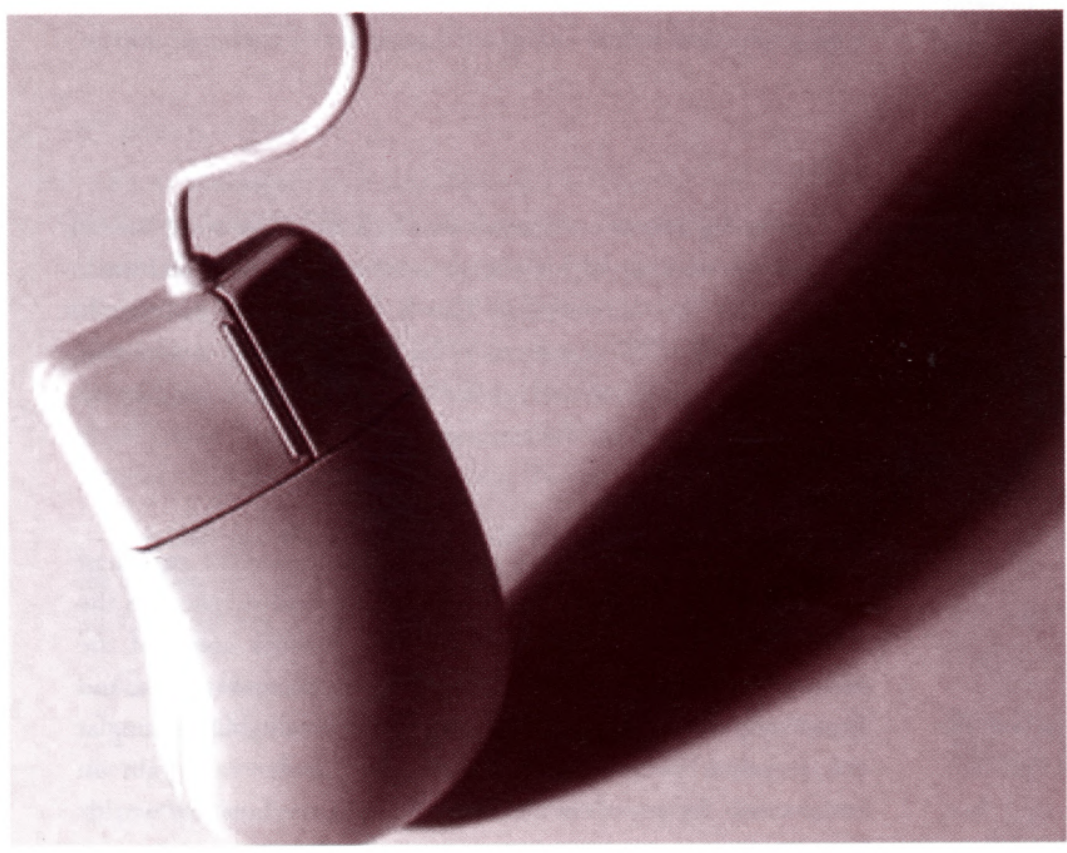

\section{THE NATURE OF THE INTERNET}

The reader may be mistaken for assuming that anybody thinking of a business idea that stood a chance of success on the Internet would have researched the areas set out below. Alternatively, an investor considering whether to invest in an Internet-related business might, if such research has not been undertaken, insist that such research be considered. Looking at some of the most recent and highly publicised examples of dotcom companies, it appears that neither the people with the ideas nor the investors have given much thought to some or all of these points.

\section{FAILURE TO DELIVER}

In general, Internet companies have failed to deliver the goods they sell. The promises made are hollow. Many orders are not delivered or are mis-delivered, and the poor after-sales service is manifest when the majority of e-mail enquiries fail to be answered. Delivery slots, when offered, are quickly taken.

First, it is important to remind ourselves that the Internet is more or less a catalogue with pages to view. To some degree the user can interact with an individual web site, and no doubt technology will develop so that the basic functionality presently available will be extended in the future. At present, all we have is a limited version of a paper catalogue.

\section{THE NATURE AND SIZE OF THE MEDIUM}

By recognising that the Internet is no more than a catalogue, the would-be Internet entrepreneur can begin to understand the market more fully, to establish how successful or otherwise their web site will be. The Internet is another version of home shopping, a method of buying goods from catalogues pioneered by the Victorians. However, after over 100 years of home shopping, the UK market remains at just over four per cent of total retail sales. This market is controlled largely by the major catalogue houses, such as Great Universal Stores and Littlewoods, who had a combined share of 36.4 per cent of the four per cent in 1998. People buying by mail order are mainly women in the $\mathrm{C} 2, \mathrm{D}$ and $\mathrm{E}$ social grades, utilising the hire-purchase or interest-free credit services to purchase the goods, few of which have computers logged on to the Internet (although they will buy from shops on the television, which Sky is presently pioneering). The number of people buying by mail order in the $\mathrm{ABC} 1$ group is minimal, although this market segment is changing, and a number of home shopping companies have targeted this group with some success.

In comparison, the US has a higher percentage of people buying from mail order catalogues. There is more use of home delivery in the US because the population has access to a postal box system, which makes it easier to deliver bulky items. In addition, the European population is generally more concentrated and therefore finds it easier to get to shops, which is demonstrated by the UK figures. Of the four per cent that buy from catalogues, 36 per cent of people in Greater London use home delivery, whilst 47 per cent shop from home in Wales. 
It is noteworthy, however, that US Government figures for retail electronic trading for the last quarter of 1999 amounted to US $\$ 5.3 \mathrm{bn}$, which is half that predicted. This represented at best (because the figure was not seasonally adjusted) 0.6 per cent of the total retail sales of US $\$ 821.2 \mathrm{bn}$. These figures probably demonstrate that selling by way of the Internet may develop further, although payment for items is usually required immediately when ordering on the Internet. As a result, the people in the $\mathrm{C} 2, \mathrm{D}$ and $\mathrm{E}$ social grades that use the hire-purchase or interest-free credit services to purchase goods will not buy on the Internet unless they obtain credit cards or are offered comparable arrangements. It is possible that the numbers of people buying on the Internet will not reach the same levels as for catalogue sales unless novel methods of addressing this issue are developed.

That Lands' End and Interflora have both achieved sales of five per cent from their respective web sites demonstrates careful targeting of their respective markets, and a combination of well-designed web sites, easy ordering facilities and delivery systems that work.

\section{WIDER RISKS}

In a medium where a bankrupt or failing company leaves little in the way of useful assets to a potential buyer, failure to research the market and consider the risks will affect the national economy as well as the individuals who lose money.

\section{WHY HOME SHOPPING IS A SMALL MARKET}

Home shopping has not developed beyond five per cent of the retail market. There are good reasons for this. Human beings are social animals, and delight in social intercourse. Shopping by browsing through catalogues at home limit this social interaction. There is no substitution for touch, taste or inspection. In addition, delivery has to be paid for, and buying a single book from a web site will cost more in charges for postage and packing than the savings made by the reduced cost of the book.

People shop on the Internet because, it is claimed, buying on the Internet is a more pleasant experience that tramping along the high street. However, it is now generally recognised that navigating around a badly designed web site creates a similar experience to visiting the shop in person, which negates the claim that it is easier to buy what you want on the Internet. Ordering tends to be haphazard, and many traders fail to inform potential customers of their geographical location. Further, the evidence shows that web customers have no loyalty to web sites, which in turn demonstrates a failure by traders on the Internet to grasp the important point that most people in an affluent society only buy those goods where aesthetics and image appeal the most.

From this short analysis, it is clear that the Internet may succeed for the right type of business, but it will not achieve the penetration that many people claim.

The legal ramifications for getting the nature of the market wrong or for misunderstanding the target market may only apply if a business intends to seek a listing on the stock exchange. By this stage, the directors are usually well advised to clearly set out the limitations in the prospectus. The on-line bookstore Amazon went even further recently and strongly advised shareholders that the prospects for future profits were very slim. In comparison, small businesses that fail to understand the nature of the Internet and subsequently lose money in setting up a trading establishment based on a web site can only blame themselves for neglecting to research the market thoroughly. Taking legal action against the sales team will meet with the usual argument that the marketing was mere 'puff'.

\section{THE INTERNET BUYER}

A further commonly-made assumption about the Internet is that every person in a household with a computer and a connection to the Internet is a potential buyer. Those who use the Internet are mainly aged 45 to 55 with access to the Internet at work, spending an average of $£ 1,000$ a year. In the main, the employer pays for the employee to obtain access to the Internet. Between 30 and 40 per cent of the time an employee is on the Internet is not related to work, and the average time spent on the Internet at work is six hours each week. Other figures indicate that many employees trade from work, search for new jobs and visit chat rooms. It could be argued that if employers begin to take this issue seriously, and restrict the use of the Internet by employees, the market for selling on the Internet may wither as a result. Only time will provide the answer.

The legal problems, in this instance, are for employers to resolve by way of e-mail and Internet policies that form part of the contract of employment.

\section{FAILURE TO DELIVER}

It is also assumed that people want home delivery of everything, thus increasing the amount of free time in their busy lives. This assumption fails to accord with the evidence, which will be considered later. In general, Internet companies have failed to deliver the goods they sell. The promises made are hollow. Many orders are not delivered or are mis-delivered, and the poor after-sales service is manifest when the majority of email enquiries fail to be answered. Delivery slots, when offered, are quickly taken. There are few weekend and evening deliveries and grocery orders that cannot be fulfilled include substitute items that are not suitable. In addition, complicated procedures mean returning unwanted goods can be difficult for the customer, although it can only be a matter of time before such procedures are challenged as unfair by consumers.

\section{CATALOGUE}

By recognising that the Internet is no more than a catalogue, the would-be Internet entrepreneur can begin to understand the market more fully, to establish how successful or otherwise their web site will be.

The limits on home delivery reinforce the problems. One person driving a van designed for urban distribution of 7.5 tonnes gross weight, including the load, can deliver to a maximum of 275 homes in a week. If only 10 per cent of the 6,000 customers serviced by supermarkets each day decided to opt for home delivery through the Internet, 600 customers would be asking for home delivery on the same or next day. It 
would be interesting to know how many extra vans would be needed to fulfil this modest size of deliveries across the country, the effect the increased number of vans would have on the local traffic conditions and the additional operating costs. To take this point one stage further, if every trader on the Internet became a success story despite the lack of evidence that people will buy from catalogues, the increase in traffic congestion would be serious.

When considering the practical implications of delivering perishable and bulky goods, it becomes easier to understand why the five top selling goods on the Internet are books, software, CDs and videos, computer peripherals and stocks, although it is pertinent to note that even books do not have a big market. Amazon have five per cent of the book market in the USA and two per cent of the UK market. This illustrates why bookshops have been the fastest to respond to the threat from Internet sales. Such items can be delivered easily - usually through the mailbox. These goods are not time dependent, and busy shoppers using the Internet from work do not have to wait for delivery. If bulky goods are to be delivered, somebody must be at home to receive them. However, social trends show that there are more single people living alone and more couples work. As a result, the only people at home are the retired and unemployed, neither group that is considered to spend money on the Internet.

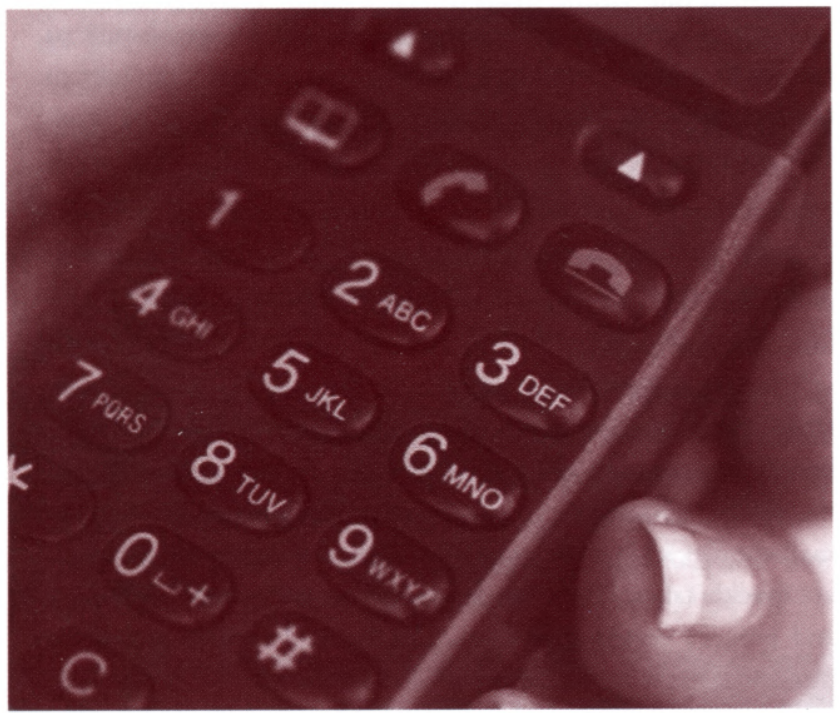

Solutions to the problem of home deliveries are varied. In the USA, Webvan has begun to establish a national delivery infrastructure. The aim is to allow Internet companies to have goods delivered to a central warehouse. Vans will then be used to deliver locally, but this solution will always have its physical limitations. This service also allows the customer to give the item back to the driver if they do not want the package. This reduces the procedural method of returning goods, and would be helpful to an Internet company in conforming to the EU Directive on distance selling (97/7/EC, 20 May 1997), which has to be implemented by member states on or before 4 June 2000. The government has responded to the directive with the Consumer Protection (Contracts Concluded by Means of Distance Communication) Regulations 2000, which established the right of the customer to cancel a contract for no reason within seven working days. Incidentally, many e-commerce traders are not aware of the terms of the directive, and are certainly not aware that they must inform the customer of this right.
Another solution is to distribute goods by the same methods as used in Japan. The buyer places an order on the web site and subsequently collects and pays for the goods at the local combini, or convenience store. These stores are used regularly, and buying goods in this way also resolve the difficulties about the security of payment over the Internet.

\section{THE MOBILE TELEPHONE MARKET}

Finally, there is a great deal of interest in obtaining access to the Internet by way of mobile telephones. This is exemplified in the recent round of bidding for the new mobile telephone licence fees which has raised over $£ 20$ bn for the government. It is assumed by the mobile telephone companies and others that millions of people will use such telephones to obtain access to the Internet and that traders will be able to sell goods and services via the mobile telephone. This assumption is incorrect. The obligations imposed on traders selling on the Internet by the distance selling directive and the proposal for a European Parliament and Council Directive on certain legal aspects of electronic commerce in the internal market (COM (1994) 427, final 98/0325 (COD)) will prevent most goods and services being sold by way of mobile telephones. It will be interesting to know whether the business planners have spoken to the lawyers.

\section{CONCLUSION}

It seems clear that many people in business have failed to research the market sufficiently to adapt their business model to sell at a distance. Generally, it does not appear that there is much evidence to show that researching the market is considered necessary when developing a web site on the Internet.

It can be argued that this is a healthy attitude, and that nothing would be done if risks were not taken. This argument may have been correct to apply to the age of the railway when the information age was in its infancy. If a railway company collapsed, some other company would take over the assets and the railway line would continue to be developed to completion. Shareholders and suppliers lost money, but the railway was in place. It can hardly be argued that this will occur in the Internet world. A web site costing millions can be removed at the flick of a switch. What is left? Nothing but an image that will be soon forgotten. Failing to use the enormous amount of information available before spending on certain failure can, at best, be described as irrational

\section{TOP SELLERS}

When considering the practical implications of delivering perishable and bulky goods, it becomes easier to understand why the five top selling goods on the Internet are books, software, CDs and videos, computer peripherals and stocks, although it is pertinent to note that even books do not have a big market.

The reader may think this article appears to be an attack on the commercial uses of the Internet. This is not the case. Its aim is to indicate how people in business fail to consider proper research before making decisions. The Internet worked for Chris Battle, the butcher who found a niche market by 
supplying cooked meats to expatriate nationals living abroad. In turn, the author has recently become the CEO of a dot-com company based in Cambridgeshire. In a medium where a bankrupt or failing company leaves little in the way of useful assets to a potential buyer, failure to research the market and consider the risks will affect the national economy as well as the individuals who lose money.

Recent research carried out by Pegasus Research International for Barrons found that 52 of the 207 Internet companies in the US will run out of cash by the end of this year.
Investors are known to be waiting for the moment the cash runs out. We can expect similar failures in the UK in due course. (c)

(C) Stephen Mason, 2000

Stephen Mason is a barrister who specialises in e-commerce, information technology and contract law. He has agreed to provide the legal content in a new version of the 'Risk Management' chapter of the Encyclopedia of Information Technology Law. E-mail:scwm@scwm.co.uk.
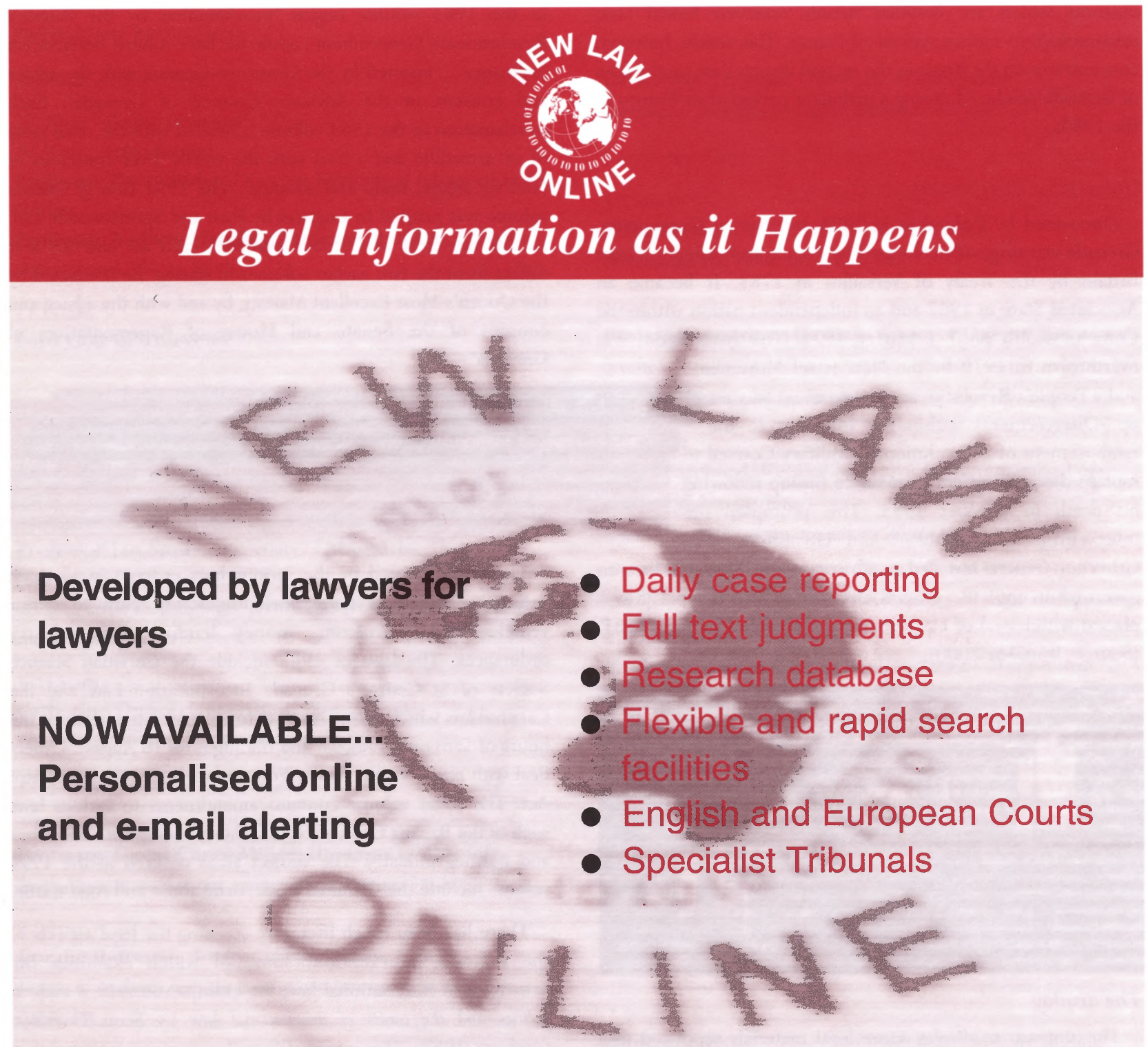

Register now for a FREE TRIAL Tel: 02074055434 Fax: 02074055693 E-mail: info@newlawonline.com Website: www.cchnewlaw.co.uk 